\title{
Localized Learning Revisited
}

\author{
Malmberg, Anders; Maskell, Peter
}

Document Version

Final published version

Publication date:

2005

\section{License \\ CC BY-NC-ND}

Citation for published version (APA):

Malmberg, A., \& Maskell, P. (2005). Localized Learning Revisited. DRUID - Danish Research Unit for Industrial Dynamics.

Link to publication in CBS Research Portal

\section{General rights}

Copyright and moral rights for the publications made accessible in the public portal are retained by the authors and/or other copyright owners and it is a condition of accessing publications that users recognise and abide by the legal requirements associated with these rights.

\section{Take down policy}

If you believe that this document breaches copyright please contact us (research.lib@cbs.dk) providing details, and we will remove access to the work immediately and investigate your claim. 


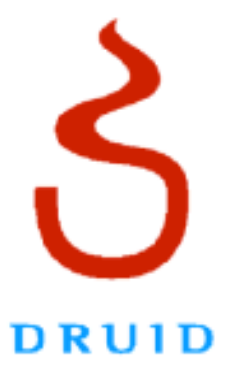

DRUID Working Paper No. 05-19

Localized Learning Revisited

By

Anders Malmberg and Peter Maskell 


\title{
3
}

D R U 1 D

\section{Localized Learning Revisited}

\author{
Anders Malmberg \\ Department of Social and Economic Geography \\ and Centre for Research on Innovation and Industrial Dynamics (CIND) \\ Uppsala University \\ P.O. Box 513, S-751 20 Uppsala, Sweden \\ E-mail: anders.malmberg@kultgeog.uu.se \\ Peter Maskell \\ Danish research Unit for Industrial Dynamics (DRUID) \\ Department of Industrial Economics and Strategy (IVS) \\ Copenhagen Business School (CBS) \\ Solbjergvej 3, $3^{\text {rd }}$ floor, DK-2000 Frederiksberg, Denmark \\ E-mail: maskell@cbs.dk
}

\begin{abstract}
:
The concept of localized learning outlines how local conditions and spatial proximity between actors enable the formation of distinctive cognitive repertoires and influence the generation and selection of skills, processes and products within a field of knowledge or activity. The localized learning argument consists of two distinct yet related elements. One has to do with localized capabilities that enhance learning while the other concerns the possible benefits that firms with similar or related activities may accrue by locating in spatial proximity of one another. In this essay, we disentangle these two inherent elements of the concept, review some of the critique that has been raised against it, and sort out some misunderstandings that we think are attached to its present use.
\end{abstract}

Key words: Knowledge, Proximity, Capabilities

JEL Codes: D83, O31

ISBN 87-7873-185-2 


\section{Introduction}

Localized learning outlines how local conditions and spatial proximity between actors enable the formation of distinctive cognitive repertoires and influence the generation and selection of skills, processes and products within a field of knowledge or activity. Localized learning helps explain why there is regional economic specialization, why similar and related firms tend to co-locate to form clusters, why both these phenomena reproduce over time, and why high-cost locations can be the home for relatively mundane economic activities despite the formation of competitive global markets.

The discourse of localized learning emerged mainly as a response to some influential claims put forward by the mid 1990s arguing that the impact of geographical space on the actions and undertakings of firms was dwindling. The "end of geography" and the "death of distance" were catch phrases signaling that, thanks to the unprecedented progress of transportation and communications technologies, and the parallel erosion of trade barriers and diffusion of best practice technologies, it was becoming increasingly possible to carry out almost any type of economic activity in almost any location. Geography was history. What you can do here, you can equally well do there - or indeed anywhere.

The development of the concept of localized learning was also a response to a prominent line of thinking that was generally downplaying the economic role of knowledge creation - and its context arguing instead that markets could be fully understood by analyzing the dynamics of supply and demand. As such, localized learning contributed with an account of contemporary industrial transformation that emphasized how the current economic development of a specific region or country cannot be separated from the particular endowment of social, cultural and institutional patterns with which it is intimately related.

The genealogy of the concept is reflected in its usage, though it is often overlooked that the localized learning argument therefore consists of two rather distinct elements: One has to do with localized capabilities that enhance learning while the other concerns the possible benefits that firms with similar or related activities may accrue by locating in spatial proximity of one another.

The aim of this essay is to disentangle these two inherent elements of the concept of localized learning, to review some of the critique that has been raised against this concept, and to sort out some misunderstandings that we think are attached to its present use. ${ }^{1}$

\footnotetext{
${ }^{1}$ The present authors have - together, individually, and in collaboration with others - contributed to the development and dissemination of various versions of the concept of localized learning. When we are critical over some of the shortcomings of the concept and its attached models of thought, this is consequently a selfcriticism as much as anything else.
} 
The essay is structured as follows. Section two discusses the concept of localized capabilities and how it has been developed in response to claims that globalization is gradually reducing the economic impact of space and place. In section three we outline in some detail the processes of interaction that underpin localized learning. In section four we try to counter some of the misunderstandings surrounding the concept of localized learning. In section five we discuss, by way of conclusion, whether the recent surge in outsourcing/off-shoring does in any fundamental way remove or shake the foundation for the localized learning concept and associated models of thought.

\section{Localized capabilities: The social and institutional underpinning of learning}

Localized learning has from the outset been applied when analyzing the impact of geographical location on firms' ability to create and sustain competitiveness in an era of economic globalization.

There are at least three broad questions lurking in the background here. The first - and most general question is concerned with the nature of competition in today's economy, and how the performance of firms and industries relate to space and place. The second is related to why geographical areas tend to specialize in particular types of economic activity and why the resulting patterns of spatial clustering of similar and related economic activities are so durable. The third question, finally, has to do with the specific issue of how high-cost regions can sustain competitiveness and prosperity in an increasingly integrated world economy. In a way, the same answer has been provided to all three questions: it has to do with learning in general and with the development of distinct and valuable localized capabilities that promote and guide learning processes into particular trajectories.

The concept of localized capabilities is thus formulated in relation to globalization. What factors of production have become more ubiquitous, i.e. available at almost identical cost and quality regardless of their location? And what factors in demand become decisive for the distribution of economic activities by remaining difficult to move or imitate? In previous writings (notably Maskell et al. 1998, Maskell and Malmberg 1999a,b) we argued that globalization is a process that actively converts previously rare and valuable localized factors into ubiquities, thus the formulation of the rather monstrous concept of an ongoing, perhaps accelerating, "ubiquitification process". What has not become globalized, it was argued, are some forms of knowledge creation and exchange that are still very much rooted in the cultural, institutional and social structures of particular places. The original argument, thus, was that some preconditions for knowledge creation remain local while pretty much everything else have become increasingly globalized.

This line of thinking, in principle, applies to all kinds of regions and all kinds of economic activities. All that it says is that location patterns will never be determined by ubiquities, but that firms locate 
and build their competitive advantages in interaction with localized capabilities. ${ }^{2}$ These might be chiefly associated with a region's natural resource endowments, infrastructure and built environment, but it is more likely today that it is the available knowledge base and institutional set-up that matter. ${ }^{3}$

The correlation at the national level between patterns of specialization in production and trade, on the one hand, and the knowledge base on the other has thus been clearly established (Archibugi and Pianta, 1992). Some evidence also supports the conjecture that particular sets of national, regional or local institutions gradually develop over time in response to the special requirements of the activities performed by firms (Friedland and Robert 1991, Choi 1993, Dobbin 1994, Maskell and Törnqvist 1999, Lundvall and Maskell 2000, Asheim 2002).

Neither the knowledge base nor the dominant institutional pattern come into existence once and for all, but are undergoing continual modifications to make them suitable to the circumstances of the time, so that the restraints imposed on the action of firms and individuals are continually changing (Cannan 1912). Once a dominating knowledge base and institutional pattern has been created it will attract those firms and individuals most compatible with it ${ }^{4}$. Together they both utilize and, by doing so, reinforce the existing knowledge base and institutional pattern, thereby setting the frame for the kind of activities that might be likely or even possible to perform presently or in the future. In an aggregate setting the process of cumulative causation favors industrial specialization and territorial differentiation and help explain why no competitive region or nation can remain a Jack-of-all-trades.

An interesting aspect of institutions is that they tend to work by preventing the exploration of excluded possibilities (Loasby 2000). Excluding possibilities carries unknown opportunity costs just as the sophistication of a particular knowledge base may prevent the performance of disparate activities deemed attractive at later stages and sometimes even result in a situation of ruinous lock-in. It is particularly difficult to un-learn successful habits of the past and institutions may be retained and sometimes even aggressively defended long after they have been made redundant by internal or external events (Hedberg 1981, Imai et al., 1986, Demsetz 1988). In less unfortunate situations the demands and requirements of firms and individuals lead to a gradual transformation of the relevant knowledge bases and institutional patterns though both might be slow in adapting to changing needs. Therefore no one-to-one correlation between industrial structure and institutional or knowledge

\footnotetext{
${ }^{2}$ Feldman and Martin (2005) use the concept of jurisdictional advantage to denote the constellations of actors and agendas that underpin the economic development of a nation or a region. Another related concept is Storper's “worlds of production” (Storper 1993).

${ }^{3}$ Following North (1994) we may view institutions as 'humanly devised constraints that structure human interaction. They are made up of formal constraints (e.g., rules, laws constitutions), informal constraints (e.g., norms of behavior, conventions, self-imposed codes of conduct), and their enforcement characteristics. Together they define the incentive structure of societies and specifically economies.' (North 1994: 360). Djelic and Quack (2003) provides an analysis of the role of institutions in the contemporary era of globalization.

${ }^{4}$ It is also one of the reasons why firms cluster and the most talented wannabes of any industry will tend to flock around the hotspots where firms in this line of business agglomerate.
} 
endowment should automatically be expected, and empirical studies continuously add to our understanding of why a complete match is seldom found and how different degrees of mismatches affect economic performance.

While certain combinations of knowledge bases and institutional patterns may develop specific lines of valuable localized learning, the localized capability line of thinking direct our attention towards the outcome of knowledge accumulation, rather than to the processes of knowledge creation. In the next section we will discuss the processes of localized learning in more detail, summarizing and evaluating the arguments advanced hitherto regarding the learning benefits of spatial proximity.

\section{Interactive learning as a localized process}

The processes of localized learning are closely related to the benefits of spatial proximity between interacting parties. Localized learning may thus refer to the enhanced knowledge creation that takes place when several co-located firms undertake similar and related activities. These benefits stem from the ease of interaction across different bodies of knowledge located in proximity of one another. Surely, a lot of effort is put into developing ICT solutions that promise to reduce the friction of space, and at least some negative consequences of dispersion might be further alleviated through increased participation in international conferences, conventions, exhibitions, trade fairs and other kinds of gatherings that aim at producing temporary spatial proximity (Maskell et al., forthcoming). Still, many types of learning continue to benefit from regular and direct face-to-face contact while other learning effects are associated with communal sharing of cognitive repertoires. The classical argument here, of course, made a distinction between tacit and codified knowledge. The more tacit the knowledge involved, the greater the dependence of spatial proximity between those taking part in its creation or exchange; the more codified the knowledge, the easier to communicate across spatial distance.

While some cognitive distance is obviously needed between partners before they become sufficiently dissimilar to learn anything from each other, we may, perhaps, assume the existence of an upper limit beyond which the cognitive distance becomes increasingly costly to overcome. It is often difficult, and sometimes almost impossible, to transfer and re-use knowledge even if it is openly available, but usually less so when the transfer takes place between firms that share language, beliefs, judgments and values. All kinds of inter-firm learning are enhanced because spatial proximity provides them with an arsenal of instruments to obtain and understand subtle and complex information of possible relevance. The ability to benefit fully from knowledge heterogeneity among firms or individuals is, consequentially, closely related to spatial proximity through cognitive correspondence but also by sharing a common history, identical jurisdictional order and equivalent factor costs. 
Three sources of localized learning processes have thus been identified (cf Malmberg and Maskell 1997, 2002). All three relate to time-geography and the fact that spatial proximity makes face-to-face interaction easier (less costly, time consuming, tiresome) and tends to carry with it an element of social, cultural and not least cognitive proximity.

The first two sets of sources of localized learning relate to the two dimensions - vertical and horizontal - along which the division of labor may develop. The third is based on the assertion that spatial proximity increases the likelihood of fruitful unanticipated encounters among key players outside the workplace and helps incorporate the insights, opinions and ideas from a broader community of informed observers, not all of whom are necessarily directly involved in the current rent seeking activities (i.e. public employees; unemployed; home workers; pensioners; etc.). We argue that this third - social - dimension of spatial proximity can be seen as a neighborhood effect.

\subsection{The vertical dimension of spatial proximity: learning by interacting}

In the vertical dimension, knowledge complementarities are the most important source of relatedness. Firms specializing in different stages of a production process carried out along the vertical axis of a production chain require some kind of co-ordination as the output of one firm may be the input of another. Vertically related firms are linked through input/output-relations. They possess knowledge, experience, or skills useful for undertaking dissimilar but complementary activities.

Studies of industrial innovation quite consistently show that new products are developed in response to signals from, and often in interaction with, customer firms (Lundvall 1985, Malmberg and Power 2005). The most sophisticated and demanding customer firms are of particular importance here, especially if their demand is in some way anticipatory - i.e. helps producer firms understand what the global market will request tomorrow, or the day after tomorrow. In the context of explaining the advantages of clustering, Porter $(1990,2000)$ attributes a key role in the knowledge upgrading of a cluster to the presence of sophisticated and demanding customers. The same applies, in principle, to suppliers of technology and machinery. In this context Gertler $(1995,2004)$ has convincingly shown that the productivity effects of employing new machinery, or production technology generally, seems to be greater when technology producers and users are co-located. Industry-academia links, whether in the form of generalized spillovers or formal collaboration, are also often thought to contribute to knowledge creation in firms (Jaffe 1989, Jaffe et al. 1993, Anselin et al. 1997, Narin et al. 1997, Zucker et al. 1998, Rodríguez-Pose and Refolo 2003) and such links seem relatively often to be localized (see Malmberg and Power 2005 for a review).

However, while vertical links make up the core of much analysis of localized learning, the fact remains that few empirical studies have been able to show that vertical linkages are indeed predominantly local (Malmberg and Maskell 2002, Gordon and McCann 2005). As an argument for 
the benefits of spatial proximity they therefore seem to contribute less than previously predicted (cf. section 4 below). The relative scarcity of real world local vertical linkages urges us to redirect our attention towards alternative explanations, notably the other two candidates of spatial proximity learning benefits: the horizontal and the social dimension.

\subsection{The horizontal dimension of spatial proximity: learning by monitoring}

Many well-known examples of localized industrial systems are based on the horizontal dimension. Such spatial agglomerations are made up of several firms operating in the same industry, producing somewhat similar output. While the vertically related firms are business partners and collaborators, horizontally related firms are mainly rivals and competitors (Maskell 2001).

Closely located firms undertaking similar activities find themselves in a situation where every difference in the solutions chosen, however small, can be observed and compared. First, regarding observability, spatial proximity brings with it the special feature of spontaneous, automatic observation. Business firms often have remarkably good knowledge of the undertakings of nearby firms even if they do not make any dedicated efforts in systematic monitoring. If those neighboring firms are in a similar business, it is the more likely that the observing firm will appreciate the fine points in the relationships between inputs and processes and learn from what is considered an attractive revealed performance.

A second element is comparability. While it might be easy for firms to blame an inadequate local factor market when confronted with the superior performance of competitors located far away, it is less so when the premium producer is located in the same local environment. The sharing of common conditions, opportunities and threats make the strengths and weaknesses of each individual firm apparent to anyone who cares to take an interest. Each horizontally linked firm is provided with the information of the possibilities to improve and the incentives to do so. ${ }^{5}$ Successful experiments can easily be distinguished from the less successful by the knowledgeable local observers. Promising avenues identified by one firm will soon be available to others. Firms with similar capabilities in the horizontal dimension constantly imitate the proven or foreseeable success of each other.

While suppliers and customers in a vertically organized production chain need to interact with each other in order to do business; competitors don't. Introducing the horizontal dimension means that localized learning in part may be independent of the degree of internal interaction at least in principle. The only requirement is that several firms undertaking similar activities are placed in circumstances where they can monitor and compare each other's undertakings constantly, closely, and almost without effort or costs. Variation emanates naturally when firms possessing similar but not identical

\footnotetext{
${ }^{5}$ This is, of course, also the essence of the domestic/local rivalry component of Porter's diamond model (Porter 1990).
} 
bodies of knowledge must act on incomplete and uncertain information. Spatial proximity helps firms identify and imitate superior solutions while combining them with ideas of their own.

\subsection{The social dimension of spatial proximity: neighborhood effects}

In addition to the proximity effects that manifest themselves in interaction or encounters between colocated firms, there are processes of localized learning that are inherent in the everyday life of people working - and living - in any local setting. There are processes of information exchange - or knowledge spillovers - going on that need not be related to the conscious undertakings of firms, but are rather to be seen as unintended side effects of such undertakings. By taking up a concept introduced by Storper and Venables (2004), we have previously denoted this phenomenon local buzz (Bathelt et al. 2004). In a similar way, Owen-Smith and Powell (2002) use the notion of 'local broadcasting' and Grabher (2002a) the term 'noise' to denote the idea that there are lots of piquant and useful things going on simultaneously in a local milieu and therefore lots of inspiration and information to receive for the perceptive local actor. Buzz thus refers to the information and communication ecology created by numerous face-to-face contacts as people and firms within the same industry co-locate in the same city, district or region. This buzz consists of specific information and continuous updates of this information; intended and unanticipated learning processes in organized and accidental meetings; the application of the same interpretative schemes and mutual understanding of new knowledge and technologies; as well as shared cultural traditions and habits, which taken together makes interaction and learning less costly. Actors continuously contribute to and benefit from the diffusion of information, gossip and news by just 'being there' (Gertler 1995).

Firms that are located in the same place are also able to understand the local buzz in a meaningful and useful way. The reason is, as already noted, that spatial proximity stimulates firms to develop similar language, technology attitudes and interpretative schemes (Lawson and Lorenz 1999, Maskell and Lorenzen 2004). Also, as has been suggested elsewhere (Maskell et al. 1998), trust tends to exist in local milieus as something inherited, that any ‘insider’ will benefit from by default. Local milieus thus consist of agents which are bound together by day-to-day interaction, based on the same expertise, a common set of technological knowledge and similar experience with a particular set of problemsolving techniques. Such relations can develop within a firm but also span a single organization and include other firms of a value chain (Gertler 2001). ${ }^{6}$

These processes can be seen as analogous with the neighborhood effect that has been established, for example in studies of voting behavior. In that context Johnson et al.(2005) recently identified five separate processes that produce the same outcome (i.e. they contribute to making people in a local area

\footnotetext{
${ }^{6}$ These relations and local milieus are here anticipated to generally emerge spontaneously, but their development may, of course, sometimes be helped by conscious and dedicated policy measures of various sorts (cf Lester and Piore 2004 or Cooke and Leydesdorff, forthcoming)
} 
behave in a certain - uniform or at least similar - way). The classic neighborhood effect, of course, is based on local social interaction, involving a process of 'conversion through conversation'. A saying like 'those who talk together vote together' indicates that human beings tend to adjust their preferences, norms and values to those with whom they regularly interact. Emulation, on the other hand, refers to the process whereby people choose to behave like their neighbors, even without interacting with them, on the basis of observed (or inferred) behavioral patterns. This could be seen as the everyday life correspondence to the learning process along the horizontal dimension discussed above. Environmental observation is a third mechanism identified, referring to the fact that people see or hear things in their local area and behave like their neighbors accordingly, in order to promote local interests ('where you stand depends on where you sit'). The two additional mechanisms identified in research on neighborhood effects - environmental selection and local pressure respectively - are arguably more related to our notion of localized capabilities than to the effects of spatial proximity per se.

All in all, we argue that there is support for the claim that spatial proximity does make possible certain types of interactive learning and that a division of processes of localized learning into the vertical, the horizontal and the social realm is a useful way to identify in more detail how they come about. In the next section, we will take on some of the more powerful arguments that have been raised against the importance of localized learning.

\section{The Global-Local Interface to Learning Dynamics}

The aspect of localized learning that deals with the benefits of proximity between interacting partners has become an issue of rather heated debate in recent years. At least three different lines of criticism take on the assertion that interactions between co-located partners should have other, superior, qualities than interactions with distant partners.

One is essentially empirical and based on evidence of limited interaction between co-located firms even when they are active in similar lines of business and form localized clusters (Tödtling and Kaufmann 1999, Koschatzky and Stenberg 2000, Henry and Pinch 2001, Britton 2003, Cumbers et al. 2003, Nadvi and Halder 2005). Oinas (1999), for instance, finds that there is relatively little empirical evidence supporting conjectures about the predominance of localized learning and that "it seems evident that the creation of new knowledge (learning) might be best viewed as a result of a ‘combination’ of close and distant interactions” (Oinas 1999: 365).

Further support for criticism is found in studies indicating that firms may well have their most sophisticated customers or hardest rivals in distant parts of the world while apparently performing as well or even better than firms reporting mainly local key relations and interactions (see Malmberg and 
Power, 2004 for a review of this type of evidence). The fact that firms often have collaborative partners and peers in far away locations have occasioned concerns as to whether the significance of local context has, perhaps, been over-emphasized in the geography of learning discourse and that explanatory models of localized learning have became overly introvert. Boschma's (2005) critique is particularly elaborate here. He argues that the impact of spatial proximity on processes of interactive learning must be examined in relation to other dimensions of proximity - notably cognitive, organizational, social and institutional. He claims that spatial proximity "per se is neither a necessary nor a sufficient condition for learning to take place: at most, it facilitates interactive learning, most likely by strengthening the other dimensions of proximity" (Boschma 2005: 62) and that "there is a strong need to isolate analytically the effect of geographical proximity from the other forms of proximity to determine whether geographical proximity really matters in processes of innovation”. Boschma also takes a critical stance towards the emphasis on the economic virtues of proximity, and points to the fact that too much proximity leads to a lack of openness and flexibility with negative impacts on learning and innovation due to the problem of lock in.

The third type of criticism is of a conjectural nature, based on the idea that dense interacting populations of various kinds of individuals can emerge within a certain trade or profession (Brown and Duguid 1991, Wenger 1998, Cetina 1999, Wenger and Snyder 2000, Amin and Cohendet 2004). Permanent or temporary "communities of practice" ${ }^{7}$ or "epistemic communities" may develop relations of trust and shared cognitions that augment interactive learning and alleviate the friction of exchanging even tacit knowledge, despite being globally dispersed. This line of thinking has also found its way into the field of urban research, where cities are now sometimes situated in the discourse of “distanciated economic flows and networks” (Amin and Thrift 2002).

There are two issues at stake here, and substantial misunderstanding seem to prevail in both cases, when it comes to what the localized learning argument amounts to. The first issue is whether spatial proximity has an impact on processes of interactive learning. The localized learning argument is that spatial proximity will tend to strengthen cognitive proximity by developing a common institutional, social and cultural setting. Learning is enhanced because proximity brings interacting parties together not only in space but also in perception. In addition, localized learning may involve spillover effects that work their way through more or less automatic processes of observation, monitoring, benchmarking and informal information exchange such as buzz. Despite Boschma's (2005) critical stance, his conclusion that spatial proximity will tend to reinforce other forms of proximities is actually in support of the existence of localization effects in processes of learning and innovation. Exactly how important these effects are can of course be debated, but not the mechanism as such.

\footnotetext{
${ }^{7}$ Wenger defines communities of practice as "groups of people who share a concern or a passion for something they do and learn how to do it better as they interact regularly." (See further http://www.ewenger.com/theory/index.htm, retrieved October 28, 2005)
} 
The second issue has to do with whether and how a local milieu should be linked to its wider ultimately global - surrounding. For some reason, the localized learning argument has sometimes been read as if a region - or a cluster - could, or even should, be self-sufficient in knowledge terms, and that the learning or innovation outcome would be greater, the more local interactions dominate over extra-local links. This is, in our view, a plain misunderstanding. We would like to make it clear, that neither the argument of localized processes of interactive learning nor the existence of localized capabilities do in any way presuppose that most interaction should be local; that it is better with more local than global interaction; or that the most important capabilities are geared towards local interaction.

We have previously addressed this issue by using the concept of global pipelines (Bathelt et al. 2004). Owen-Smith and Powell (2002) originally used the term 'pipeline' to refer to the channel used in distant interactions. They argue that even though knowledge spillovers may be more effective within a regional network than across its borders, some of the decisive, non-incremental knowledge flows are often generated through 'network pipelines'. Access to new knowledge does not just result from local and regional interaction but is often acquired through strategic partnerships of inter-regional and international reach. Firms are thus not only embedded in regional innovation networks but also in social networks which are not defined regionally or by any other discrete spatial level (see also Grabher 2002b,c and Scott 2002). ${ }^{8}$

While much of the interaction and information exchange within a local environment - the buzz - is characterized by being frequent, broad, relatively unstructured and largely "automatic", pipelines function in a different way. A potential partner from the outside has to be found, it has to be decided how much information should be given to that partner and to which degree the activities of that firm have to be monitored or controlled. The resulting interaction is thus impacted by the degree of trust that exists between the firms. Unlike in the case of local relations between co-located firms (Maskell and Malmberg 1999a), there is no initial shared trust in this situation from which the new partners can benefit. Instead, the establishment of global pipelines with new partners requires that new trust is being built in a conscious, systematic and incremental way. This process of building up trust takes time and involves costs (Williamson 1985, Dasgupta 1988, Harrison 1992).

The extra-local knowledge flows (through the pipeline system) can be expected to connect to the local buzz, in such a way that the two become mutually reinforcing. The more developed the pipelines that 'pump' information and news about markets and technologies into the local milieu, the more dynamic the buzz from which local actors benefits. Because of their potential to intensify local interaction, global pipelines strengthen the internal selection and translation processes in the local milieu.

\footnotetext{
${ }^{8}$ There is, of course, a certain similarity between the idea of spatially extended links between a defined set of related firms and the notion of sectoral systems of innovation as developed by Malerba (2002).
} 
Others have pointed to the existence of tradeoffs between initial cognitive distance and subsequent investments in alleviating mechanisms. Such investments can only render positive results if the actors involved are sensitive to the nature and complexity of the knowledge in question (Sorenson et al. 2005). If optimal cognitive distance for knowledge creation is curvilinear (inverted U), attempts to source knowledge in far away and dissimilar settings run the risk of running into insurmountable barriers for interactive learning (Capello 1999, Nooteboom et al. 2005, Wuyts et al. 2005). Under such circumstances increased exposure to diverse perspectives through potent pipelines may not spur creativity or yield superior ideas, and localized learning in the high-cost environments will suffer from increased fragmentation as globalization proceeds. An interesting line of inquiry have expanded the idea that there are qualitative differences between local and global networks and interactions, but that it is important for any local milieu to establish and maintain inflows of new knowledge from the outside as well as mechanisms for integrating it into the existing knowledge pool (Giuliani 2002, 2005a,b, Aage 2005). Successful long distance learning is possible either by creating knowledge overlap through cross-organizational labor mobility (Saxenian and Hsu 2001) or by building an appropriate absorptive capacity (cf Cohen and Levinthal 1990, Tushman and Katz 1980). In both cases, dedicated investments in establishing new bridging instruments become important precursors.

\section{$5 \quad$ Localized learning: conclusions and challenges}

The argument provided so far brings us back to the basic Hayekian insight, hinted at in the initial quote of this essay. Knowledge of the relevant facts is initially dispersed among many people (Hayek 1945). Its mobilization as part of learning efforts implies a collaborative combination rather than a mere aggregation. Knowledge mobilization therefore relies upon the pre-existence of shared cognitive models of the world. Collaborative efforts in knowledge creation and exchange are facilitated among individuals who share values and identity. These features underpin the localized character of knowledge creation. The argument forwarded so far in this essay can be summarized in five bold points.

First, the concept of localized learning has been shown to consist of two distinct, albeit related elements: the existence of localized capabilities that underpin and give direction to processes of knowledge creation or exchange on the one hand, and the existence of benefits of spatial proximity in processes of interactive learning on the other.

Second, as to the function of localized capabilities, we have emphasized that they develop over time in relation to the dominant economic structure of the region in question, that they have certain directional effects on the development of the knowledge-base of a region, and that they can either hinder or foster the development of a competitive position in the globalized knowledge-based economy. The definitional aspect of the concept, however, is that regardless of the fact that the ongoing globalization 
will lead to the erosion - or indeed ubiquitification - of certain previously localized factors of production, there will always be infrastructural, social and institutional characteristics that make one region different from another. Such distinctive features will matter tomorrow as well.

Third, the benefits of spatial proximity between interacting parties may be analyzed along three dimensions of a local economic setting: the vertical, the horizontal and the social dimension. Presumably, the magnitude and importance of localized interactions along the vertical setting have been exaggerated in the literature on economies of spatial clustering in recent years.

Fourth, while we acknowledge that relations of cognitive proximity can be developed over distance and across various barriers, we maintain that there are 'neighborhood effects' that, ceteris paribus, will always, in an almost automatic way, tend to create a degree of overlap between spatial and other forms of proximity. This is the essence of the proximity aspect of the localized learning argument and as we see it, it has not so far been successfully challenged.

Fifth and finally, we have argued that our insistence of the importance of localized learning should not be interpreted as saying that local interaction is always superior to extra local interaction. To the contrary, we claim that the ability to build of well functioning network relations - pipelines - to knowledge sources around the globe is in itself perhaps one of the most important localized capabilities.

An obvious question today is whether the latest phases of globalization do or may in any fundamental way alter the preconditions of localized learning as they have been outlined in this essay. The extent to which interactive learning processes can be spatially extended depends, among other factors, on the epistemological qualities of the knowledge involved, and the mechanisms giving rise to inclusion and exclusion. In other words, the content, context and means applied can hinder or foster the formation of collaborative relations and affect how they may unfold in geographical space.

There are at least three ways in which contemporary changes in the global political economy may significantly impinge on the spatial extension of interactive learning processes.

First, new conditions for global trade have emerged as an outcome of successful global trade agreements; the formation of internationally recognized regulating or supervising authorities; a global banking system; the increased harmonization of consumer preference and technical standards; and dramatic improvements in infrastructure, logistics and transport systems including ICT.

Second, new governmental policies in particular in the major, former third world countries, have eliminated many previous restrictions on technology transfer and collaboration; led to the abolishment of local ownership requirements, invited foreign $R \& D$ investments; prioritized technical and managerial education; and encouraged returnee entrepreneurship. 
Third, and finally, new corporate strategies have radically increased the number of internationally operating enterprises; helped to reduce cognitive distances by advanced training and mobility programs or by creating internal labor markets; as well as enhanced the ability to capture local knowledge assets and to follow an upward learning curve also when meeting increasingly sophisticated local demand.

To elaborate further on the third point, much of the current growth in international economic relations takes the form of captive offshoring to transplants or affiliates under managerial control by the outsourcing firm. A growing proportion of activity is however established in the form of new, independent suppliers that meet many current quality and delivery requirements at a fraction of previous costs. These low-cost providers now span activities from simple production and assembly of predefined modules, over provision of administrative functions and services to scientifically sophisticated or intellectually challenging designs or R\&D deliverables.

The emergence of open global markets for an array of highly competent suppliers in low-costs settings offers great rewards to any incumbent not overly concerned with the possible ensuing long-term increase in vulnerability when offshoring most or all of the tasks previously performed in-house or by domestic or regional suppliers. Early movers' success can, in turn, compel their competitors and local suppliers to follow suit when they realize how abstaining from reaping the short-term benefits of offshoring might easily prevent them from being around to witness whatever future backlash they may fear. The resulting intensification in offshoring, and consequential severing of many local ties, will undoubtedly help firms in high-cost environments increase their productivity and profitability to the benefit of present customers or shareholders or both. On a broader scale the process is arguably the first stage in a true convergence of long-standing global differences in levels of economic growth and development.

On the flip side we find complex challenges to almost all aspects of economic life in the hitherto most economically developed parts of the world. One such challenge concerns the ability to uphold a viable environment for localized learning in high-cost regions when globalization processes gain significance. There is no guarantee that the parts of the world that have so far been able to prosper most from localized learning are also able to do so in the future. The possible erosion of some crucial localized capabilities in the high-cost environments in the OECD world should, however, not be taken to indicate that the mechanisms of localized learning have ceased to exist. For example, intensified localized learning in the IT/Software/Telecom sectors have become apparent during the last decade in many smaller or larger city regions in several Asian countries (e.g. Shanghai or Beijing in China, Bangalore in India, Malaysia's multimedia "super corridor", Seoul, Daejeon and Suwon in Korea or the Hsinchu region in Taiwan) as well as in a Latin American country like Mexico (e.g. Monterrey, Guadalajara or Mexico City, and with Chihuahua moving rapidly in the same direction). 
The spatial extension of interactive learning processes heralded by offshoring strategies seems to go hand in hand with the formation of new hotspots of localized learning. That someone may now do things better there, than they used to be done here, does not imply that things could be done equally well anywhere. Successful globalization means strengthening rather than weakening the conditions for localized learning.

Acknowledgement. The argument presented in this essay has been developed in discussion and collaboration with a number of friends and colleagues over the years. We would in particular like to thank those colleagues with whom we have in the last few years co-written some of the papers in which elements of ideas developed here originate: notably Harald Bathelt, Mark Lorenzen, and Dominic Power. The usual disclaimers, of course, apply. 


\section{REFERENCES}

Aage,T. (2005) External information acquisition by industrial districts and the impact of different knowledge creation dimensions. The case of the fashion and design branch of the industrial district of Montebelluna, NE Italy. Unpublished PhD Thesis, IVS, Copenhagen Business School.

Amin, A. and Cohendet, P. (1999) Learning and adaptation in decentralised business networks. Environment and Planning D: Society and Space 17: 87-104.

Amin, A. and Cohendet, P. (2004): Architectures of Knowledge. Firms, Capabilities and Communities, Oxford: Oxford University Press.

Amin, A. and Thrift, N.J. (2002) Cities: Rethinking the Urban. Cambridge: Polity Press.

Anselin, L., Varga, A. and Acs, Z. (1997). Local geographic spillovers between university research and high technology innovations, Journal of Urban Economics 42: 422-448.

Archibugi, D. and Pianta, M. (1992) The Technological Specialization of Advanced Countries, Dordrecht: Kluwer.

Asheim, B.T. (2002) Temporary organisations and spatial embeddedness of learning and knowledge creation, Geografiska Annaler: Series B, Human Geography 84 (2): 111-124.

Barley, S. R., and Tolbert, P. S. (1997). Institutionalization and structuration: Studying the links between action and institution. Organization Studies, 18(1), 93-117.

Bathelt, H., Malmberg, A. and Maskell, P. (2004) Clusters and knowledge: local buzz, global pipelines and the process of knowledge creation Progress in Human Geography 28 (1): 31-56.

Boschma, R.A. (2005) Proximity and Innovation: A Critical Assessment. Regional Studies 39 (1): 61-74.

Britton, J.N.H. (2003): Network structure of an industrial cluster: electronics in Toronto. Environment and Planning A 35 (6): 983-1006.

Brown, J.S. and Duguid,P. (1991): Organizational Learning and Communities of Practice: Towards a Unified View of Working, Learning and Innovation. Organization Science 2 (1): 40-57.

Burns, J., and Scapens, R. W. (2000). Conceptualizing management accounting change: an institutional framework. Management Accounting Research, 11: 3-25.

Cannan, E. (1912): The history of local rates in England in relation to the proper distribution of the burden of taxation, London: P.S.King \& Son, Orchard House.

Capello, R. (1999): SME clustering and factor productivity: A Milieu production function model. European Planning Studies 7 (6): 719-736.

Cetina, K.K. (1999): Epistemic Cultures: How the Sciences Make Sense, Chicago: Chicago University Press.

Choi, Y. B. (1993) Paradigms and conventions: Uncertainty, Decision Making and Entrepreneurship, Ann Arbor: University of Michigan Press.

Cohen, W. M. and Levinthal, D. A. (1990) Absorptive-capacity - A new perspective on innovation and learning. Administrative Science Quarterly 35 (1): 128-152. Cooke P. and Leydesdorff L. (forthcoming) Regional Development in the Knowledge-Based Economy: The Construction of Advantage Journal of Technology Transfer.

Cumbers, A., MacKinnon, D. and Chapman, K. (2003): Innovation, collaboration, and learning in regional clusters: a study of SMEs in the Aberdeen oil complex. Environment and Planning A 35 (9): 16891706.

Dasgupta,P. (1988): 'Trust as a Commodity'. In: Gambetta,D., (Ed.) Trust: Making and Breaking Cooperative Relations pp. 49-72. Oxford: Blackwell.

Demsetz, H. (1988) The Organization of Economic Activity. Volume I: Ownership, control and the firm, Oxford: Blackwell.

Djelic, M.-L., and Quack, S. (Eds.) (2003). Globalization and institutions: Redefining the rules of the economic game. Cheltenham, UK: Edward Elgar Publishing.

Dobbin, F. (1994). Forging industrial policy. The United States, Britain, and France in the railway age. Cambridge: Cambridge University Press.

Feldman, M. and Martin, R. (2005): Constructing jurisdictional advantage. Research Policy 34 (8): 1235-1249.

Friedland, R. and Robert R. A. 1991. Bringing Society Back In: Symbols, Practices, and Institutional Contradictions. pp. 232-263 in The New Institutionalism in Organizational Analysis, ed. Walter W. Powell and Paul J. DiMaggio. Chicago: University of Chicago Press.

Giuliani, E. (2002): Clusters absorptive capability: An evolutionary approach for industrial clusters in developing countries. Paper presented at the DRUID Summer Conference on "Industrial Dynamics of the New and Old Economy - who is embracing whom?" Copenhagen 6-8 June 2002, URL: http://www.druid.dk/conferences/summer2002/Papers/GIULIANI.pdf

Giuliani, E. (2005): Cluster absorptive capacity - Why do some clusters forge ahead and others lag behind? European Urban and Regional Studies 12 (3): 269-288. 
Giuliani, E. (2005): Inter-firm Networks, Projects and Clusters: The structure of cluster knowledge networks: uneven and selective, not pervasive and collective. Best Young Scholar Paper presented at the DRUID Tenth Anniversary Summer Conference 2005 on "Dynamics of Industry and innovation: Organizations, Networks and Systems". URL: http://www.druid.dk/conferences/summer2005/papers/ds2005-551.pdf

Gertler, M.S. (1995) Being there - Proximity, organization, and culture in the development and adoption of advanced manufacturing technologies. Economic Geography 71 (1): 1-26

Gertler, M.S. (2001): Best practice? Geography, Learning and the Institutional Limits to Strong Convergence. Journal of Economic Geography 1 (1): 5-26.

Gertler, M.S. (2003) Tacit knowledge and the economic geography of context, or The undefinable tacitness of being (there). Journal of Economic Geography 3 (1): 75-99.

Gertler, M.S. (2004): Manufacturing Culture: the Institutional Geography of Industrial Practice, Oxford: Oxford University Press.

Gordon, I.R. and McCann, P. (2005) Innovation, agglomeration, and regional development. Journal of Economic Geography 5 (5): 523-453.

Grabher,G. (2002a): The project ecology of advertising: Tasks, talents and teams. Regional Studies 36 (3): $245-$ 262.

Grabher,G. (2002b): Cool projects, boring institutions: Temporary collaboration in social context. Regional Studies 36 (3): 205-214.

Grabher,G. (2002c): Fragile sector, robust practice: project ecologies in new media. Environment and Planning A 34 (11): 1911-1926.

Harrison, B. (1992): Industrial Districts: Old Wine in New Bottles? Regional Studies 26 (5): 469-483.

Hayek, F.A. (1945) The use of knowledge in society American Economic Review, XXXV (4): 519-530.

Hedberg, B. (1981) 'How organizations learn and unlearn', in P. C. Nyström and W. H. Starbuck (eds) Handbook on Organizational Design - Adapting Organizations to their Environment, Oxford: Oxford University Press.

Henry,N. and Pinch,S. (2000): Neo-Marshallian nodes, institutional thickness, and Britain's 'Motor Sport Valley': thick or thin? Environment and Planning A 33: 1169-1183.

Imai, K.-I., Nonaka, I. and Takeuchi, H. (1986) 'Managing the new product development process: how Japanese companies learn and unlearn', in K. B. Clark, R. H. Hayes and C. Lorenz, (eds) The uneasy alliance. Managing the productivity--technology dilemma, Boston: Harvard Business School Press.

Jaffe, A. (1989) Real effects of academic research, American Economic Review 79: 957-970.

Jaffe, A., Trajtenberg, M. and Henderson, R. (1993). Geographic localization of knowledge spillovers as evidenced by patent citations, Quarterly Journal of Economics 108: 577-598.

Johnston, R., Propper, C., Sarker, R., Jones, K., Bolster, A. and Burgess, S. (2005) Neighbourhood social capital and neighbourhood effects. Environment and Planning A 37 (8): 1443-1459.

Koschatzky,K. and Stenberg,R. (2000): R\&D cooperation in innovation systems. Some lessons from the European Regional Innovation Survey. European Planning Studies 8 (4): 487-502.

Lawson, C. and Lorenz, E. (1999) Collective learning, tacit knowledge and regional innovative capacity, Regional Studies 33 (4): 305-317.

Lester, R.K. and Piore, M.J. (2004) Innovation — The Missing Dimension, Cambridge, Ma: Harvard University Press.

Loasby, B.J. (2000) Market institutions and economic evolution. Journal of Evolutionary Economics 10 (3): 297 $-309$.

Lundvall,B.-Å. (1985): Product Innovation and User-Producer Interaction. Industrial development research series no.:31, Aalborg.: Aalborg Universitetsforlag

Lundvall, B.-Å. and Maskell, P. (2000) Nation states and economic development: from national systems of production to national systems of knowledge creation and learning. In: Clark, G.E., Feldman, M.P. and Gertler, M.ES. (eds) The Oxford Handbook of Economic geography. Oxford: Oxford University Press.

Malerba, F. (2002) Sectoral systems of innovation and production, Research Policy 31: 247-264.

Malmberg, A. and Maskell, P. (1997) Towards an explanation of regional specialization and industry agglomeration. European Planning Studies, Vol. 5 (1): 25-41.

Malmberg, A. and Maskell, P. (2002) The elusive concept of localization economies: towards a knowledgebased theory of spatial clustering, Environment and Planning A 34 (3): 429-449.

Malmberg, A. and Power, D (2004) On the Role of Global Demand in Local Innovation Processes. In: Fuchs, G. and Shapira, P. (eds) Rethinking Regional Innovation and Change - Path Dependency or Regional Breakthrough? New York: Springer.

Malmberg, A. and Power, D (forthcoming) (How) do (firms in) clusters create knowledge? Accepted for publication in Industry and Innovation. 
Maskell,P. (2001): Towards a Knowledge-based Theory of the Geographical Cluster. Industrial and Corporate Change 10 (4): 919-941.

Maskell, P., Bathelt, H. and Malmberg, A. (forthcoming) Building Global Knowledge Pipelines: The Role of Temporary Clusters. Accepted for publication in European Planning Studies.

Maskell, P. and Lorenzen, M (2004) The cluster as market organization. Urban Studies 41 (5-6): 991 - 1009.

Maskell, P. and Malmberg, A. (1999a) Localised learning and industrial competitiveness, Cambridge Journal of Economics, 23 (2): 167-185.

Maskell, P. and Malmberg, A. (1999b) The competitiveness of firms and regions - 'Ubiquitification' and the importance of localized learning, European Urban and Regional Studies 6 (1): 9-25.

Maskell, P. and Törnqvist, G. (1999) Building a Cross-Border Learning Region. The Emergence of the Northern European Øresund Region. Copenhagen: Copenhagen Business School Press

Maskell, P., Eskelinen,H., Hannibalsson,I., Malmberg,A. and Vatne,E. (1998): Competitiveness, localised learning and regional development. Specialisation and prosperity in small open economies, London: Routledge.

Nadvi,K. and Halder,G. (2005): Local clusters in global value chains: exploring dynamic linkages between Germany and Pakistan. Entrepreneurship and Regional Development 17 (5): 339-363.

Narin, F., Hamilton, K. and Olivastro, D. (1997) The increasing linkage between US technology and public science, Research Policy 26: 317-330.

Nooteboom,B., Vanhaverbeke,W., Duysters,G., Gilsing,V. and Oord,A.v.d. (2005): Optimal cognitive distance and absorptive Capacity. Mimeo, Tilburg University, the Netherlands

North, D.C. (1994) Economic Performance through time American Economic Review, 84(3): 359-368.

Oinas, P. (1999): Activity-specificity in organizational learning: implications for analysing the role of proximity. GeoJournal 49: 363-372.

Owen-Smith, J. and Powell, W.W. (2004): Knowledge Networks as Channels and Conduits: The Effects of Formal Structure in the Boston Biotechnology Community. Organization Science 15 (1): 5-21.

Porter, M. E. (1990) The competitive advantage of nations. Basingstoke: Macmillan.

Porter, M. E. (2000) Locations, clusters and company strategy. In: Clark, G.E., Feldman, M.P. and Gertler, M.ES. (eds) The Oxford Handbook of Economic Geography. Oxford: Oxford University Press.

Rodríguez-Pose, A. and Refolo, M. (2003) The link between local production systems and public and university research in Italy, Environment and Planning A 35: 1477-1492.

Saxenian,A. and Hsu,J.-Y. (2001): The Silicon Valley-Hsinchu Connection: Technical Communities and Industrial Upgrading. Industrial and Corporate Change 10 (4): 893-920.

Scott, A.J. (2002): A new map of Hollywood: the production and distribution of American motion pictures. Regional Studies 36: 957-975.

Sorenson,O., Rivkin,J.W. and Flemming,L. (2005): Complexity, Networks and Knowledge Flows. Paper presented at the DRUID Tenth Anniversary Summer Conference 2005 on "Dynamics of Industry and innovation: Organizations, Networks and Systems". URL: http://www.druid.dk/conferences/summer2005/papers/ds2005-596.pdf

Storper, M. (1993) Regional worlds of production - Learning and Innovation in the technology districts of France, Italy and the USA. Regional Studies 27 (5): 433-455.

Storper,M. and Venables,A.J. (2004): Buzz: Face-to-face contact and the urban economy. Journal of Economic Geography 4 (4): 351-370.

Tödtling,F. and Kaufmann,A. (1999): Innovation Systems in Regions of Europe - A comparative perspective. European Planning Studies 7 (6): 699-717.

Tushman,M.L. and Katz,R. (1980): External communication and project performance: An investigation into the role of gatekeepers. Management Science 26 (11): 1071-1085.

Wenger,E. (1998): Communities of practice: Learning, meaning, and identity, Cambridge: Cambridge University Press.

Wenger,E. and Snyder,W.M. (2000): Communities of Practice: The Organizational Frontier. Harvard Business Review Jan-Feb.: 139-145.

Williamson,O.E. (1985): The Economic Institutions of Capitalism, New York: The Free Press.

Wuyts,S., Colombo,M.G., Dutta,S. and Nooteboom,B. (2005): Emperical tests of optimal cognitive distance. Journal of Economic Behavior and Organization 58(2): 277-302.

Zucker, L., Darby, M. and Torero, M. (2002) Labor mobility from academe to commerce, Journal of Labor Economics 20(3): 629-660. 